\title{
A Revista Perspectivas em Ciência da Informação e seu panorama científico no período 2010 a 2014
}

\begin{abstract}
Wanderley Pivatto Brum
\end{abstract}
\begin{abstract}
Professor da Faculdade Avantis de Ensino (Balneário Camboríu), Santa Catarina.Mestre em Ensino de Ciências Naturais e Matemática, Faculdade Avantis de Ensino, Santa Catarina
\end{abstract}

Jesiel Sildo da Cunha

Graduando em Sistemas de Informação pela Faculdade Avantis de Ensino. Faculdade Avantis de Ensino, Santa Catarina

Victor Hugo Gressler Pianezzola

Graduando em Sistemas de Informação pela Faculdade Avantis de Ensino. Faculdade Avantis de Ensino, Santa Catarina

http://dx.doi.org/10.1590/1981-5344/2651

O presente trabalho tem por objetivo analisar a produção da Revista Perspectivas em Ciência da Informação, no período de 2010 a 2014, tendo como critérios os apontados pela Scientific Eletronic Library Online (SciELO) como política e visibilidade dos periódicos brasileiros. Caracteriza-se essa investigação como documental. Para a análise, buscou-se observar, no período analisado da revista, as categorias: artigos, referências, autores dos artigos, editoração e financiamento. A partir da análise empreendida, os resultados apontam predominância de artigos originais, redigidos em português e as fontes referenciadas, equilibra-se por livros e textos em português. Conclui-se que, há uma predominância de artigos publicados em português, o que poderá ser repensado pela revista, caso a opção da mesma seja pela internacionalização; assim, nesse caso, há a necessidade da publicação de artigos principalmente em língua inglesa, ampliação do número de avaliadores e membros do corpo editorial vinculados a instituições estrangeiras. 
Palavras-chave: Produção científica; Análise bibliométrica; Perspectivas em Ciência da Informação.

\title{
The Jornal Perspectives on Information Science and panorams scientific period from 2010 to 2014
}

\begin{abstract}
This study intends to analyze the Perspectives on Information Science production, in the period between 2010-2014, with the criterion indicated by the Scientific Electronic Library Online (SciELO) as a political and visibility of Brazilian journals. This investigation is characterized as documentary. For the analysis, it sought to observe, for the period of the journal, the categories: articles, references, authors of articles, publishing and financing. From the analysis undertaken, the results indicated a predominance of original articles written in Portuguese and referenced sources is balanced by books and texts in Portuguese. In conclusion, there is a predominance of articles published in Portuguese, which could be reconsidered by the journal if the option is for the internationalization; thus, in this case, there is the need to publish articles primarily in English, increasing the number of reviewers and members of the editorial board linked to foreign institutions.
\end{abstract}

Keywords: Scientific production; Bibliometric analysis; Perspectives on Information Science.

Recebido em 08.12.2015 Aceito em 18.05.2016

\section{Introdução}

As bases de dados existentes têm como prioridade reunir produções científicas de pesquisadores para a socialização dos trabalhos, de modo a contribuir para o avanço da ciência. Contudo, tais bases de dados possuem políticas e critérios de permanência para os periódicos que delas fazem parte, os quais estão sujeitos a avaliações constantes balizadas por procedimentos e exigências.

A Scientific Eletronic Library Online (SciELO), enquanto um dos maiores indexadores de periódicos da América Latina, lançou novos procedimentos, a serem implantados a partir de 2015, para admissão e permanência de periódicos brasileiros em sua coleção, entre os critérios que mais sobressaem está a indicação de internacionalização dos periódicos, incluindo pesquisadores internacionais nos conselhos 
editoriais, para avaliação de originais, bem como a inserção de autores internacionais nos volumes e publicações em língua inglesa.

Embora se tenha um discurso de internacionalização, há também um discurso de que se necessita melhorar a qualidade das produções nacionais e dos periódicos, mas existe 0 fato de que, muitos pesquisadores de renome ainda busquem revistas internacionais para a publicação de suas pesquisas, o que enfraquece, de certo modo, a produção brasileira (MENEGHINI, 2012).

Os periódicos possuem uma função importante, no sentido que trazem as inovações e resultados de pesquisas, em vários campos, de forma contínua. Para Packer (2011) o caráter científico dos periódicos é oriundo de trabalhos originais que são submetidos e aceitos pelos mesmos, após processo de revisão por avaliadores e atendimento a políticas editoriais. Também são considerados artigos originais aqueles que realizam uma revisão, estado da arte, de um determinado campo de conhecimento.

Para a estruturação da informação bibliográfica dos artigos, que compõem as bases de dados, estão os índices SciELO, WoS e Scopus. Estes índices fornecem dados e indicadores das produções científicas, considerando artigos originais e de revisão, bem como citações que recebem e concedem. Tais índices apontados auxiliam nos processos de avaliação das produções científicas, seja de um determinado periódico, instituições, autores, ou áreas específicas (PACKER, 2011).

Assim, o presente estudo teve por objetivo realizar análise bibliométrica da produção contida na Revista Perspectivas em Ciência da Informação, no período de 2010 a 2014, à luz dos limitadores apontados pela SciELO para o aumento da visibilidade internacional dos periódicos brasileiros.

A bibliometria constitui-se em uma área da Ciência da Informação. Por meio de um processo de evidenciação quantitativa de dados estatísticos de um conjunto de produções bibliográficas, a bibliometria torna-se relevante para a análise da produção científica de um periódico, tendo em vista que seus indicadores podem demonstrar como se comporta ou se desenvolve a produção científica de uma área do conhecimento (ARAúJO; ALVARENGA, 2011).

\section{Metodologia}

Do ponto de vista dos procedimentos técnicos adotados, o presente estudo se caracteriza como documental (GIL, 2008). O corpus documental é constituído por artigos publicados na Revista Perspectivas em Ciência da Informação, no período de 2010 a 2014, volumes de 15 a 19.

Quanto às categorias e variáveis que foram analisadas a partir do corpus documental, são as seguintes: Artigos - tipo, idioma, temática e tempo de aceite; Referências - média de referências por artigo, tipologia, média em anos das referências, idioma da fonte e revistas citadas; Autores dos artigos - número de autores por artigo; quantidade de 
publicação por autor; sexo e vínculo institucional; Editoração e financiamento - membros da equipe editorial e financiamento.

A partir da leitura, dos trabalhos publicados na revista, foi possível identificar a tipologia do estudo (original, revisão, ensaio, comunicação ou tradução). A área temática foi analisada a partir das palavras-chaves elencadas pelos autores dos textos.

Em relação ao tempo de aceite, levantou-se o número de dias entre a submissão e o aceite dos trabalhos, e calculada a média. Os artigos que tinham somente a data do aceite foram desconsiderados. A identificação do idioma deu-se na leitura, considerando os idiomas aceitos (português, inglês, francês e espanhol).

Com relação à média de referências, realizou-se a contagem dos trabalhos citados nos artigos publicados e esse número foi dividido pela quantidade de artigos analisados. Quanto à tipologia das fontes utilizadas, - levantamento considerou: livros, artigos de periódico, capítulo de livro, texto da internet, trabalhos em evento (anais), dissertações e teses, outros (jornal, folder, relatório, documentos, CD-ROM, texto mimeografado e digitalizado, palestra, programa de TV e entrevista). Na tipologia periódico, foram levantados os nomes das revistas científicas citadas. Adicionalmente, foi levantada a média das vezes em que as referências contidas nos artigos originais e de revisão, nos anos de 2012 e 2013, foram utilizadas no artigo.

A variável média em anos das referências utilizadas deu-se através da diferença entre $o$ ano do artigo publicado e a obra citada. Posteriormente, fez-se a média por ano das referências, somando-as e dividindo-as pela quantidade. As referências sem data, em sua maioria, provenientes de documentos disponíveis na rede mundial de computadores, foram desconsideradas. Para estabelecer o idioma utilizado nas referências foi considerado o título da obra referenciada.

Com relação à quantidade de publicação por autores, foram levantados os nomes e a ordem no artigo para detectar a frequência desses nas publicações. Foi, também, quantificado o sexo dos autores que publicaram artigos no período analisado. $O$ vínculo institucional dos autores que publicaram no periódico estudado deu-se mediante a filiação institucional declarada.

Para verificar a equipe editorial e a fonte de financiamento, verificou-se o site da revista, na página da SciELO, para visualizar os processos realizados para a publicação de uma proposição temática a Perspectivas em Ciência da Informação.

A partir dos dados levantados na revista, utilizou-se da estatística descritiva para a análise dos mesmos, para assim realizarem-se algumas reflexões acerca dos dados obtidos e das contribuições teóricas em pesquisas já realizadas acerca do tema. 


\section{Resultados e discussão}

A Revista Perspectivas em Ciência da Informação encontra-se em circulação desde 1996, e está classificada no sistema Qualis com o conceito A1 Ciências Sociais e Aplicadas, B1 Administração, Ciências Contábeis, Turismo e Interdisciplinar, B2 Educação, Arquitetura, Urbanismo, Engenharia III, Letras e Linguística, Planejamento Urbano e Regional/Demografia. Seu caráter temático é dirigido a profissionais e pesquisadores da área educacional com o propósito de abordar questões que se colocam como atuais e significativas neste campo de atuação.

A Revista Perspectivas em Ciência da Informação de acesso livre tem periodicidade trimestral. Está indexada em importantes bases de dados como a SciELO, Directory of Open Access Journals, INFOBILA - Base de Datos de Información y Bibliotecología Latinoamericana, Information Science Abstracts, INSPEC, International Bibliographie der Rezensionen Wissenschaftlicher Literatur, ISI Web of Knowledge, Latindex, Library and Information Science Abstracts, Library Literature, LICI - Literatura de Ciência da Informação, PASCAL, Scopus.

Então, por meio do levantamento na revista, do período de 20102014, realizou-se análise bibliométrica, a partir das categorias apresentadas na sequência do texto.

\subsection{Categoria artigos}

A Tabela 1 apresenta o quantitativo de edições, o número de artigos publicados anualmente e a tipologia dos artigos publicados.

Tabela 1 - Artigos publicados na Perspectivas em Ciência da Informação no período 2010-2014

\begin{tabular}{c|c|c|c|c|c|c|c}
\hline Ano & $\begin{array}{c}\mathbf{N}^{\circ} \text {. de } \\
\text { Artigos }\end{array}$ & Original & Palestra & $\begin{array}{c}\text { Relatos de } \\
\text { experiências }\end{array}$ & Ensaio & $\begin{array}{c}\text { Teses e } \\
\text { Dissertações }\end{array}$ & Entrevistas \\
\hline \hline 2010 & 82 & 48 & 1 & -- & -- & 25 & 8 \\
\hline 2011 & 70 & 50 & -- & -- & -- & 19 & 1 \\
\hline 2012 & 50 & 45 & -- & -- & -- & 5 & -- \\
\hline 2013 & 59 & 40 & -- & 4 & -- & 13 & 1 \\
\hline 2014 & 78 & 62 & -- & 1 & 1 & 14 & -- \\
\hline Total & $\mathbf{3 3 8}$ & $\mathbf{2 4 5}$ & $\mathbf{1}$ & $\mathbf{5}$ & $\mathbf{1}$ & $\mathbf{7 6}$ & $\mathbf{1 0}$ \\
\hline
\end{tabular}

Fonte: Dados da pesquisa (2015).

Dos 338 artigos, foram considerados 334. Foram desprezados 4 artigos originais publicados por não apresentar dados suficientes para tratamento.

De acordo com a Associação Brasileira de Normas Técnicas (ABNT, 2003 , p. 1) existem dois tipos de artigos, o original (scientific) e o de revisão (review). Considerando essa delimitação, tem-se na Revista Perspectivas em Ciência da Informação a predominância de artigos (334) 
$72,27 \%$, que representa mais da metade das publicações, profundidade das reflexões e riqueza em seu conteúdo.

A Revista Perspectivas em Ciência da Informação se mantém dentro dos padrões estabelecidos pela SciELO para revistas da área de Ciências Humanas: periodicidade mínima semestral e desejada quadrimestral; e, número mínimo de 50 artigos publicados por ano e número ideal 24 . Em todo o período estudado, a periodicidade foi trimestral, a média de artigos por ano foi de 67,8 e o número mínimo de artigos foi de 50 e o máximo de 82 , situando-se em um patamar próximo do máximo.

Mesmo a revista Perspectivas em Ciência da Informação aceitar a submissão de textos em outras línguas, há uma predominância, no período analisado de publicações em língua portuguesa 95,85\% dos artigos (321). Sendo eles 2,68\% (9) estão na língua espanhola e 1,49\% (5) na língua inglesa.

Para Righetti (2013), em áreas como as Ciências Humanas, em função das características locais ou regionais, a maioria dos artigos nacionais é redigida em língua portuguesa. Para Packer (2011), a publicação em português é considerada uma limitação, quando se fala sobre visibilidade internacional, contudo é uma decisão crítica para quem compõe o conselho editorial de uma revista. Ainda, para Packer (2011), se por um lado os artigos indexados em periódicos nacionais na SciELO, em 2009, apenas 32\% eram em inglês, por outro lado, dos periódicos internacionais indexados na WoS, em 2009, 98\% dos artigos foram publicados em inglês. Esse aspecto das publicações em inglês vai sendo, pouco a pouco, tomado como objetivo para periódicos brasileiros, considerando a tendência da internacionalização.

A temática dos artigos foi analisada a partir das palavras-chave contidas. Nas normas da Revista Perspectivas em Ciência da Informação é orientada a utilização de três a sete termos. Contabilizou-se que, 41 artigos apresentam três palavras-chave, 63 artigos quatro palavraschave, 100 artigos cinco palavras-chave, 39 com seis palavras-chave e, 2 com sete palavras chave. Totalizando 1123 palavras-chave, verificou-se a dispersão dos termos encontrados. As palavras-chave utilizadas dez ou mais vezes foram: ciência da informação (19), information science (17), gestão do conhecimento (12), knowledge management (13) e bibliometria (12). As palavras-chave estão adequadas ao escopo da Revista Perspectivas em Ciência da Informação.

Quanto às temáticas dos cadernos, no ano de 2010 foram as seguintes: Bases filosóficas da organização da informação; Análise sobre a configuração epistemológica da Ciência da Informação com base nas citações da produção brasileira na área; Análise de citações para avaliação do consumo de informação na revista Informação \& Sociedade e ao uso do portal CAPES por pesquisadores das áreas de Ciências Biológicas, Linguística, Letras e Artes e Ciências Humanas da UFMG.

Já no ano de 2011, teve-se como tema A Escola; Juventude e Ensino Médio: território de práticas, marcos legais e formação; Sociologia: permanências e novos desafios. Para o ano de 2012, Cenas para a Infância: personagens da literatura e de desenhos animados; Corpo, 
Educação Física e Sociedade: diálogos em tempos e espaços; Identidade Profissional: Memórias Escolares e Narrativas Docentes.

Em 2013, as temáticas apresentadas nos cadernos versaram sobre Alfabetização: Dimensões políticas, pedagógicas e narrativas docentes; Alfabetização em foco: experiências para compartilhar e desafios a enfrentar; Educação Matemática e Surdez. Para o ano de 2014, os cadernos apresentaram artigos em torno dos seguintes temas - Imagem e Ciência: perspectivas educacionais e pedagógicas dos documentos imagéticos; Educação das Pessoas com deficiência no Brasil; Educação e Trabalho.

No que se refere ao prazo de avaliação, este depende do processo de julgamento dos manuscritos. O prazo entre a submissão e o aceite no período analisado é: de 101 a 150 dias para 14,97\% (50) dos artigos publicados, de 201 a 250 dias para 62,27\% (209). Períodos superiores iguais ou superiores a 251 dias atingiram um percentual de 20,95 \% (70). Todos os artigos apresentavam a data de submissão e aceite, o que demonstra uma rigorosidade metódica significativa, como elemento importante para a manutenção da indexação, segundo as normas estabelecidas pela SciELO no quesito tempo médio de submissão e aprovação dos textos:

O tempo médio de processamento dos manuscritos deve ser de até 6 (seis) meses, considerando o tempo entre as datas de submissão e de decisão final quanto à publicação, e de até 12 (doze) meses, considerando o tempo entre as datas de submissão e publicação do manuscrito. Entretanto, recomenda-se um ciclo total médio de 6 (seis) meses considerando a tendência internacional (SCIELO, 2014, p. 13).

O que se pode perceber é que a Perspectivas em Ciência da Informação está bem próxima de atender este item, mas ainda há que ocorrer melhorias quanto à agilidade do processo, pelo que visualiza-se em termos de tempo médio entre o recebimento do artigo e o aceite contido no material no período investigado.

\subsection{Categoria referências}

A Revista Perspectivas em Ciência da Informação estabelece que as referências deverão obedecer a NBR-6023/2002, da Associação Brasileira de Normas Técnicas (ABNT). A exatidão das referências constantes na listagem e a correta citação no texto são de responsabilidade do(s) autor(es) dos trabalhos, que devem se certificar de que todas as menções autorais ao longo do texto estejam devidamente contempladas nas referências.

A Tabela 2 apresenta o número de artigos publicados e de referências contidas nesses e a média de referências utilizadas por ano. 
Tabela 2 - Média de referências utilizadas nos artigos publicados na Perspectivas em Ciência da Informação, no período 2010-2014

\begin{tabular}{c|c|c|c}
\hline $\begin{array}{c}\text { Ano da } \\
\text { publicação }\end{array}$ & $\begin{array}{c}\mathbf{N} \cdot{ }^{\circ} \text { de artigos } \\
\text { publicados }\end{array}$ & N. ${ }^{\circ}$ de referências & Média de referência por artigo \\
\hline \hline 2010 & 82 & 1029 & $21,44(\mathrm{DP} \pm 3,12)$ \\
\hline 2011 & 70 & 1221 & $24,42(\mathrm{DP} \pm 2,73)$ \\
\hline 2012 & 50 & 1216 & $27,02(\mathrm{DP} \pm 2,96)$ \\
\hline 2013 & 59 & 1002 & $25,05(\mathrm{DP} \pm 2,81)$ \\
\hline 2014 & 78 & 1181 & $19,05(\mathrm{DP} \pm 4,42)$ \\
\hline Total & $\mathbf{3 3 9}$ & $\mathbf{5 6 4 9}$ & $23,39(\mathrm{DP} \pm \mathbf{3 , 2 0})$ \\
\hline
\end{tabular}

Fonte: Dados da pesquisa (2015).

Nos artigos publicados, verificou-se uma variação entre 9 e 81 referências. Segundo Matos et al. (2012), a qualidade não ocorre em função do número de referências, porém, evidencia-se a preocupação do(s) autor(es) com a construção de um referencial teórico congruente com a realidade, possibilitando análises mais aprofundadas. Constatou-se, no presente estudo, a média 23,39 (DP $\pm 3,57$ ) referências por artigo. Ainda, constatou-se que, 49,35\% (2788) das referências foram citadas apenas uma vez. A média de citação das referências foi de 11,87 (DP \pm $3,16)$. Além disso, $0,74 \%$ (42) das referências não constavam citadas no texto. Esses dados merecem destaque na medida em que muitas referências são utilizadas para comparações ou concordância com afirmações.

A Tabela 3 apresenta a tipologia das referências utilizadas nos artigos publicados no período analisado. São consideradas todas as referências apresentadas nos 241 artigos analisados no presente estudo.

Tabela 3 - Tipologia da fonte utilizada nos artigos publicados na Perspectivas em Ciência da Informação no período 2010-2014

\begin{tabular}{c|c|c}
\hline Tipo da Fonte & Número de referência & Frequência (\%) \\
\hline \hline Livro e/ou capítulos de livros & 2485 & 43,99 \\
\hline Artigos de periódicos & 1652 & 29,24 \\
\hline Textos da internet & 372 & 6,59 \\
\hline Anais & 321 & 5,68 \\
\hline Dissertações e Teses & 298 & 5,28 \\
\hline Outros & 521 & 9,22 \\
\hline Total & $\mathbf{5 6 4 9}$ & $\mathbf{1 0 0}$ \\
\hline
\end{tabular}

Fonte: Dados da pesquisa (2015).

O resultado tem ligação direta com a tipologia dos artigos produzidos, considerando-se que a utilização de livros, normalmente, em artigos originais não possibilita a recuperação de dados empíricos secundários, produzindo limites. No que se refere às Ciências Humanas, estas dão prioridade à produção de livros, propondo novas ideias e reflexões acerca de um tema de pesquisa (CARVALHO; MANOEL, 2006). A 
predominância de livros foi, também, constatada nos estudos de Araújo e Melo (2011); bem como em Liberatore, Herrero-Solana e Guimarães (2007), e Packer (2011).

Entre os livros, a referência que obteve maior número de citações foi o livro: A sociedade em rede de Castells (1999), citado 37 vezes. Em seguida, o livro: traçados e limites da ciência da informação de Pinheiro (1995), foi citado 29 vezes. Logo após a obra: a organização do conhecimento de Choo (2005), foi citada por 25 vezes. Finalizando o ranking de maiores números de citações a obra: as tecnologias da inteligência de Lévy (1993), foi citado por 19 vezes.

De forma a complementar, foi verificada a quantidade de vezes que cada referência é utilizada. Da totalidade, 3019 obras foram utilizadas uma única vez e 1312 mais de uma vez. Este resultado aproxima-se ao encontrado no estudo de Araújo e Melo (2011), constatando-se a predominância de estudos referenciados apenas uma ou duas vezes, produzindo dispersão da literatura citada.

A Tabela 4 apresenta os periódicos científicos que compõem a zona superior de citações.

Tabela 4 - Revistas científicas mais citadas nos artigos publicados na Revista Perspectivas em Ciência da Informação no período 2010-2014

\begin{tabular}{l|c}
\multicolumn{1}{c|}{ Revistas (Fator de Impacto) } & Quantidade de citações \\
\hline \hline Ciência da Informação & 160 \\
\hline Anais Da Academia Brasileira De Ciências & 134 \\
\hline Perspectivas em Ciência da Informação & 155 \\
\hline Scientometrics & 66 \\
\hline Transinformação & 45 \\
\hline Journal of the American Society for Information Science & 29 \\
\hline Journal of Documentation & 26 \\
\hline DataGramaZero & 25 \\
\hline Information Systems Management & 12 \\
\hline Informação \& Informação & 6 \\
\hline
\end{tabular}

Fonte: Dados da pesquisa (2015).

Observa-se, considerando as revistas mais utilizadas, que o impacto dessas é relativamente baixo. Em termos práticos, tem-se que referências mais utilizadas pela comunidade científica internacional, principalmente de estudos com maior amplitude, não são utilizadas. Para Meneghini (2012), as principais causas estão situadas nas características locais e regionais das pesquisas e o inglês. Em relação ao idioma das referências, o português representa o maior percentual $(69,28 \%)$, na sequência, inglês $(17,98 \%)$ e espanhol (12,74\%). Segundo Packer (2011), o número de artigos científicos publicados em inglês em revistas brasileiras integrantes da SciELO Brasil saltou de 38\% em 2007 para 52\% em 2011. Além disso, também aumentou a publicação de artigos bilíngues (em português e inglês). 
Na Tabela 5 é apresentada, por ano de publicação do artigo, a média em anos das referências utilizadas.

Tabela 5 - Média em anos das referências utilizadas nos artigos publicados na Revista Perspectivas em Ciência da Informação, no período 2010-2014

\begin{tabular}{|c|c|}
\hline Ano da publicação & Média em anos das referências \\
\hline 2010 & $16,12(\mathrm{DP} \pm 2,73)$ \\
\hline 2011 & $12,78(\mathrm{DP} \pm 1,97)$ \\
\hline 2012 & $14,23(\mathrm{DP} \pm 2,15)$ \\
\hline 2013 & $18,32(\mathrm{DP} \pm 3,12)$ \\
\hline 2014 & $17,24(\mathrm{DP} \pm 2,98)$ \\
\hline Total & $15,73(D P \pm 2,59)$ \\
\hline
\end{tabular}

Fonte: Dados da pesquisa (2015).

Existem situações onde referências com mais de um século, representando no presente trabalho por nove $(0,98 \%)$, elevaram os valores. Nesse sentido, o desvio padrão foi utilizado para demonstrar o comportamento dos dados em torno da média.

Como o Factor Impact (FI) dos periódicos utilizados nas referências (pouco mais de $9 \%$ das referências apresentaram FI maior do que 0,5 ), optou nesse caso, por não discutir a meia vida dos artigos citados. A meia vida diz respeito à metade do tempo em que uma pesquisa é útil (STREHL, 2005).

Reforçou-se ainda esta questão, partindo da explicação de Strehl (2005, p. 24), sobre a relação existente entre obsolescência e FI:

$\mathrm{Na}$ definição da forma sincrônica de medir a obsolescência, tem-se que, quanto maior o número de referências recentes citadas nos artigos de um dado periódico, maior é o ritmo de obsolescência das informações por ele veiculadas e vice-versa. Utilizando-se essa abordagem, fica ainda mais evidente a relação existente entre obsolescência e FI. Se o cálculo do indicador é feito com base nos dados das citações feitas aos artigos nos três primeiros anos após a publicação, as áreas como as ciências sociais e humanidades e os setores da ciência aplicada, como as engenharias e a computação, que apresentam altíssima proporção de trabalhos que não são citados nos cincos primeiros anos após sua publicação [...], terão consequentemente impacto muito menor [...] do que as publicações das disciplinas de ciências biológicas e física, que geralmente são citadas assim que publicadas.

No caso da área de Artes e Humanidades, está apresenta o maior número de artigos que não são citados nos cinco primeiros anos, ocasionando este aspecto mencionado por Strehl (2005), que a área 
possui artigos, frutos de pesquisa, que causam menor impacto (AMIN; MABE, 2000).

\subsection{Categorias autores dos artigos}

A quantidade de autor por artigo demonstrou variação entre um e seis autores, da seguinte maneira: um autor em 164 (48,38\%) dos artigos publicados, dois autores em 82 (24,19\%), três autores em 33 $(9,73 \%)$, quatro autores em $29(8,55 \%)$, cinco autores em um $(3,54 \%)$, seis autores em 19 (5,60\%). Para o período analisado, portanto, os dados demonstram um predomínio de autoria individual.

Farias (2009) infere que $74,2 \%$ dos artigos, publicados em periódico da área das Humanas, apresentam até três autores. Na Revista Perspectivas em Ciência da Informação, no período 2010-2014, o quantitativo de até três autores foi encontrado em 279 artigos, o que perfaz $82,30 \%$ dos artigos. Para o autor, este perfil assemelha-se às áreas Sociais e Aplicadas, as quais favorecem o trabalho isolado ou em um número reduzido de colaboradores, o que se configura também no periódico em análise.

Os artigos, em sua maioria, são redigidos em língua portuguesa e perfazem um quantitativo de $72,23 \%$ (242), sendo que deste montante 85,53 \% (207 artigos) são escritos por autores de nacionalidade brasileira; e, 27,76\% (93 artigos) por autores de outras nacionalidades que optaram por redigir artigos em língua portuguesa.

Dentre os artigos redigidos em língua portuguesa e com vinculação internacional há 13 de autoria individual, oito artigos com dois autores, quatro artigos com três autores, e três artigos em quarteto. Neste universo, comparecem as seguintes nacionalidades dos autores: inglesa (25), espanhola (9), argentina (8), italiana (8), norte-americana (7), japonesa (7) e portuguesa (5); têm-se, então, 53 artigos e 69 autores $(23,18 \%)$.

Os demais, 35 dos artigos $(10,47 \%)$, são redigidos em língua francesa e inglesa. Dentre os artigos redigidos em língua inglesa e francesa, encontram-se as seguintes nacionalidades de seus autores: americana (23), francesa (14), canadense (3) e argentina (2). Constatase ainda que, dos 35 artigos, 18 são de autoria individual, 12 em duplas e cinco em trio, quantificando 57 autores $(11,15 \%)$ que redigiram artigos em língua inglesa e francesa.

Foram identificados 602 autores que produziram 338 artigos, destes $473(61,24)$ têm nacionalidade e vinculação brasileira, sendo responsáveis por 207 artigos; e, 129 (22,52\%) dos autores possuem outras nacionalidades e são responsáveis por 131 artigos. Buscou-se levantar, também, o sexo dos autores. Notou-se a predominância masculina em $70,9 \%$ (427 autores) e 30,7\% de mulheres (175 autoras).

Ressalta-se, ainda, que dentre o universo de autores a imensa maioria é composta de doutores com vinculação universitária (284 autores), 27 autores são mestres e 18 apenas possuem graduação. 
Verifica-se que a produção não se concentra em um grupo de autores, pois não se observa no período nenhum artigo com repetição de autoria. Portanto, a lei do elitismo de Price (o número de membros da elite corresponde à raiz quadrada do número total de autores, e a metade do total da produção é considerada como critério para saber se a elite é produtiva ou não), não se aplica no contexto analisado da Perspectivas em Ciência da Informação, no período de 2010 a 2014.

Com relação aos autores, analisou-se a vinculação institucional, de modo que, identificou-se 52 instituições, das quais: 36 são nacionais $(69,23 \%)$ e 16 instituições internacionais $(30,76 \%)$.

No que diz respeito às instituições nacionais a Universidade Federal de Minas Gerais (UFMG) lidera o número de incidências com 49 vinculações, todavia uma vinculação baixa considerando o número total de instituições que publicaram no período analisado, não configurando produção científica endógena e demonstrando a seriedade e rigorosidade organizacional e metódica do periódico em análise.

Têm-se, também, outras nove instituições com incidências repetidas de vinculação, sendo que, com 49 incidências a instituição (Universidade Federal de Santa Catarina - UFSC); já com 19 incidências há uma instituição (Universidade de Brasília - UNB). Com 14 incidências contabilizaram-se a instituição (Universidade Federal da Paraíba - UFPB). Com 13 incidências a instituição (Universidade Federal do Paraná - UFPR); já com oito incidências tem-se a instituição (Universidade Estadual Paulista - UNESP) e subsequente com sete incidências a instituição (Universidade de São Paulo - USP) e com cinco incidências tem-se a duas instituições (Universidade Estadual de Londrina - UEL e Universidade Federal do Rio Grande do Norte - UFRN).

A partir das incidências de vinculação institucional e sua localização no território nacional, vê-se a existência da concentração dos vínculos na região sul (67) e sudeste brasileira (64).

No que tange à vinculação institucional internacional, das 16 instituições encontradas, três instituições apresentam incidências repetidas: a Universidade Harvard, nos Estados Unidos, Universidade Baylor, nos Estados Unidos e a Universidade de Oxford, do Reino Unido lidera as menções com três incidências; a Universidade de Michigan nos Estados Unidos, contabilizou duas incidências. No tocante à localização territorial das vinculações internacionais existe a predominância de nove vínculos no continente Norte Americano (com instituições universitárias dos EUA e canadense), cinco incidências internacionais da América do Sul (com vinculação argentina e colombiana), duas incidências na Europeus (de instituições francesas).

\subsection{Categoria editoração e financiamento}

Nas informações contidas no sítio do SciELO, sobre a Perspectivas em Ciência da Informação, pode-se extrair informações sobre a editoração e financiamento. A revista possui a sua equipe editorial composta por uma editora (professora da UFMG), com um editor adjunto (professor da 
UFMG). O Conselho Editorial composto por cinco membros da Escola de Ciência da Informação da UFMG. Além desses encontra-se o Conselho Consultivo composto por 22 membros, os quais estão ligados a quinze instituições brasileiras e cinco internacionais. Embora, estejam presentes conselheiros de universidades estrangeiras, a predominância é de conselheiros brasileiros, o que pode denotar ainda uma necessidade de busca de parceiros em instituições de outros países para uma internacionalização da revista.

Os editores (associados ou de seção ou outra denominação) são pesquisadores com afiliação nacional ou estrangeira, reconhecidos na área sob sua responsabilidade e seus currículos atualizados devem estar disponíveis online.

Quando cientistas ou personalidades são referenciados por motivo honorário ou para agregar prestígio ao periódico sem entretanto participar ativamente na gestão editorial, os nomes devem ser listados separadamente sob denominação correspondente que evidencie que não atuam como editores na gestão dos manuscritos.

Os periódicos indexados pelo SciELO devem maximizar a internacionalização do corpo de editores. A partir de janeiro de 2016, os periódicos indexados no SciELO devem atender às porcentagens mínimas esperadas e recomendadas de editores associados ativos com afiliação institucional no exterior, segundo a área temática e para a coleção toda [...] (SCIELO, 2014, p. 11).

No setor de infraestrutura, a Escola de Ciência da Informação da Universidade Federal de Minas Gerais ampara a Revista Perspectivas em Ciência da Informação, de onde derivam as publicações periódicas desde 1996. Além da UFMG, há apoio da Coordenação de Aperfeiçoamento de Pessoal de Nível Superior (CAPES) e ao Conselho Nacional de Desenvolvimento Científico e Tecnológico (CNPQ).

Desde 2009, a Revista Perspectivas em Ciência da Informação opera pelo sistema SciELO de publicação, o qual utiliza-se do Open Journal System como suporte de gerenciamento eletrônico e que realiza a publicação de periódicos científicos:

A Coleção SciELO Brasil indexa, disponibiliza e dissemina online em acesso aberto textos completos de periódicos científicos do Brasil de todas as áreas do conhecimento que publicam predominantemente artigos inéditos resultantes de pesquisa científica original, que utilizam o procedimento de avaliação por pares dos manuscritos que recebem ou encomendam e que apresentam desempenho crescente nos indicadores de cumprimento dos critérios de indexação. A coleção privilegia a admissão e permanência dos periódicos 
que em sua operação avançam na profissionalização, internacionalização e modelos de financiamento sustentável (SCIELO, 2014, p. 7).

A revista possui atualmente, somente a versão online de acesso livre. Consta que, a revista aceita colaborações de pesquisadores da área educacional, reservando-se o direito de aceitá-las ou não a depender das propostas dos cadernos temáticos e normas de editoração, sendo avaliadas pelo Corpo Editorial. Uma das exigências para a publicação de um caderno temático é que se tenha, entre os autores, ao menos um autor internacional, o que aponta para a iniciativa de internacionalização. Além disso, é uma exigência de órgãos de fomento e da própria SciELO a partir de 2015, para que as revistas sejam inseridas ou mantidas no sistema.

A avaliação do corpo de editores associados, editores ad hoc, pareceristas e autores dos últimos 3 (três) fascículos publicados leva em conta a representatividade nas respectivas comunidades assim como a distribuição institucional e geográfica das suas afiliações institucionais. A concentração institucional ou geográfica é considerada como limitante para a admissão do periódico na coleção, enquanto a internacionalização do corpo de editores, pareceristas e autores é considerada um indicador positivo (SCIELO, 2014, p. 22).

Todo o processo de proposição, envio e avaliação dos artigos para a composição dos números da revista é gerenciado pela plataforma on-line. Há normas específicas para a formatação dos textos, o que é exigido como um dos itens para aprovação.

Os originais são enviados, previamente, ao Comitê Editorial. Este encaminha aos relatores que possuem a autoridade para aceitar ou rejeitar os textos. No caso da solicitação de revisão, a mesma é enviada ao organizador do caderno e este encaminha aos autores para que sejam contempladas as solicitações. É utilizado para esse processo o sistema avaliação cega, ou seja, a Gerência da Revista escolhe os avaliadores para que seja feito a avaliação e leitura das provas.

Uma das indicações expressas pela SciELO (2014) é que as revistas ampliem a participação de pareceristas estrangeiros na avaliação de trabalhos, o que denota em mais um aspecto a questão da internacionalização, mas como explicitam Padilha et al (2014, p. 515):

[...] a internacionalização de um periódico científico é um processo que requer planejamento, dedicação, investimento financeiro e esforços da equipe editorial. Várias etapas precisam ser realizadas, sendo que a 
primeira delas é assumir que os artigos devam estar em, no mínimo, dois idiomas, um deles, obrigatoriamente, o inglês. Além disso, devem ser de acesso aberto (open access), para que sejam lidos, reconhecidos como veiculador de conhecimentos e, sobretudo, citados. A partir de então, inicia-se uma nova demanda, que é a captação de pesquisadores internacionais influentes, interessados em submeter seus manuscritos em periódicos publicados no Brasil.

As publicações em língua inglesa exigem mudanças na política editorial das revistas, e assim, como fator positivo, angariam novos leitores estrangeiros para os periódicos nacionais, o que pode gerar um movimento importante, que seria visualizar o Brasil como produtor e gerador de conhecimentos em diversos campos (PADILHA et al., 2014).

Em relação à política editorial da Revista Perspectivas em Ciência da Informação, a mesma se encontra expressa em seu sítio, considerando todo o processo para que pesquisadores proponham cadernos temáticos e a indicação de como organizar os originais que comporão os mesmos. Este aspecto coaduna com os critérios descritos pela SciELO (2014, p. 12):

Os periódicos podem adotar diferentes processos de avaliação e denominação das instâncias responsáveis que conduzem à aprovação ou rejeição de manuscritos. Entretanto, o procedimento adotado deve ser especificado formalmente nas instruções aos autores. O processo de arbitragem deve ser transparente e documentado. O autor deve ter sempre acesso ao estado de avanço da avaliação e os periódicos devem assegurar aos autores a possibilidade de recorrer das decisões editoriais.

É obrigatória a indicação nos artigos publicados das principais datas do processo de arbitragem, compreendendo pelo menos as datas de recebimento e de aprovação.

Como regra proposta está que o autor dos textos deve estar a par do processo de avaliação de seu texto, e que este seja documentado.

Quanto à propriedade intelectual, todo o conteúdo dos periódicos está sob a Licença Creative Commons do tipo atribuição BY-NC, com exceção de onde ocorra algum tipo de identificação, esse padrão foi adotado em 2015 pela Revista, consta-se que é algo recente.

\section{Considerações finais}

A Revista Perspectivas em Ciência da Informação, no período analisado de 2010-2014, publicou 334 artigos, em edições trimestrais anuais, predominando a publicação de artigos originais, redigidos em sua maioria, em português. Quanto à temática, não foi possível identificar o 
predomínio de uma área. O tempo de aceite da revista situa-se na faixa de 201 a 250 dias. Nas referências, a tipologia mais utilizada foi o livro e, em média, são utilizadas 15,73 (referências por artigo. O idioma predominante nas referências foi o português. A predominância da autoria dos artigos é masculina, sendo que não há concentração de um grupo específico de autores ou instituição.

A grande maioria dos autores é brasileira, bem como há predominância de publicações em português. As normas editoriais, na composição dos cadernos, preveem como regra a participação de, pelo menos, um autor internacional, o que aponta para a questão da internacionalização.

Percebe-se que a revista busca atender os padrões da SciELO, o que a mantém em sua coleção. Embora, observando-se os critérios de manutenção de periódicos da SciELO a partir de 2015 há pontos a serem melhorados, como por exemplo, a ampliação das publicações em língua inglesa, e o número de avaliadores e membros do Conselho Editorial ligados a instituições estrangeiras.

Uma questão interessante da Revista é que se pode observar a possibilidade de um pesquisador apresentar uma proposta para um número, com um resumo dos artigos, contemplando diferentes abordagens teóricas e diferentes instituições, o que denota uma abertura da Revista Perspectivas em Ciência da Informação quanto a vieses teóricos e a busca de contemplar, também, pesquisadores que discutem as temáticas de origens e locais diferentes.

A Revista Perspectivas em Ciência da Informação possui livre acesso. Há o apoio da UFMG, a qual sediada pela Escola de Ciência da Informação da Universidade Federal de Minas; assim como de órgãos de fomento como a CAPES e CNPQ.

Em linhas gerais, dos números analisados no período, encontram-se temáticas diversas para o embasamento teórico-prático da ação docente em suas diferentes realidades, em especial para a reflexão no campo do ensino em instituições formais e não-formais.

\section{Referências}

AMIN, M.; MABE, M. Impact factors: use and abuse. Perspectives in Publising, Amsterdam, n. 1, p. 1-6, Oct. 2000.

ARAÚJO, R. F.; ALVARENGA, L. A bibliometria na pesquisa científica da pós-graduação brasileira de 1987 a 2007. Enc. Bibli: R. Eletr. Bibliotecon., Florianópolis, v. 16, n. 31, p. 51-70, 2011.

ARAúJO, C. A. A.; MELO, M. O. T. Análise dos quinze anos do periódico Perspectivas em Ciência da Informação. Perspectivas em Ciência da Informação, v. 16, n. 4, p. 243-256, 2011.

ASSOCIAÇÃ O BRASILEIRA DE NORMAS TÉCNICAS (ABNT). NBR 6022: Informação e documentação - artigo em publicação periódica científica impressa - apresentação. Rio de Janeiro, 2003. 
CARVALHO, Y. M.; MANOEL, E. J. Para além dos indicadores de avaliação da produção intelectual na grande área da saúde. Movimento, Porto Alegre, v. 12, n. 3, p. 193-225, set./dez. 2006.

CASTELLS, M. A sociedade em rede. São Paulo: Paz e Terra, 1999.

CHOO, C. W. A organização do conhecimento: como as organizações usam a informação para criar significado, construir conhecimento e tomar decisões. São Paulo: Senac, 2003. cap. 1 e 2, p. 27-120.

FARIAS, M. C. Competência informacional e dimensões de competência do bibliotecário no contexto escolar. Perspectiva em Ciência da Informação, v.14, n.2, p.2-16, 2009.

GIL, A. C. Métodos e técnicas de pesquisa social. 6. ed. São Paulo: Atlas, 2008.

LÉVY, P. As tecnologias da iteligência: o futuro do pensamento na era da informática. Rio de Janeiro: Editora 34, 1993.

LiBERATORE, G.; HERRERO-SOLANA, M.; GUIMARÃES, A. P. Análise bibliométrica do periódico Ciência da Informação durante o período 2002004. Brazilian Journal of Information Science, v. 1, n. 2, p. 3-21, 2007. Disponível em: <http://www2.marilia.unesp.br/revistas/index.php/bjis/article/view/29>. Acesso em: 5 jul. 2015.

MATOS, E. B. S. et al. Congresso ANPCONT: análise bibliométrica descritiva e avaliativa dos artigos publicados de 2007 a 2011. Enfoque Reflexão Contábil, Maringá, v. 31, n. 3, p. 73-88, set./dez. 2012.

MENEGHINI, R. Citations to papers from Brazilian institutions: a more effective indicator to assess productivity and the impact of research in graduate programs. Brazilian Journal Medical Biological Research, v. 44, n. 8, Aug. 2012.

PACKER, A. L. Os periódicos brasileiros e a comunicação da pesquisa nacional. Revista USP, v. 89, p. 26-81, mar./maio 2011.

PADILHA, M. I. et al. A internacionalização do conhecimento e o aumento da qualidade e da visibilidade dos periódicos brasileiros. Texto Contexto Enferm, Florianópolis, v. 23, n. 3, p. 515-516, jul./set. 2014.

PAGÈS, J. Aproximación a un currículum sobre el tiempo histórico. In: RODRÍGUEZ FRUTOS, J. (Ed.). Enseñar historia: nuevas propuestas. Barcelona: Laia; Cuadernos de Pedagogía, 1989. p. 107-138.

PINHEIRO, L. V. R.; Traçados e limites em ciência da informação. Ciência da Informação, Brasília, v. 24, n. 1, p. 1-19, 1995

RIGHETTI, S. Produção científica do Brasil aumenta, mas qualidade cai. Folha de S. Paulo, São Paulo, 22 abr. 2013. Disponível em: $<$ http://www1.folha.uol.com.br/fsp/cienciasaude/105099-producaocientifica-do-brasil-aumenta-mas-qualidade-cai.shtml>. Acesso em: 8 jul. 2015. 
SCIENTIFIC ELETRONIC LIBRARY ONLINE (SCIELO). Critérios, política e procedimentos para a admissão e a permanência de periódicos científicos na Coleção SciELO Brasil. 2014. Disponível em: <http:// Novos Criterios_SciELO_Brasil.pdf >. Acesso em: 10 jul. 2015.

STREHL, L. O fator de impacto do ISI e a avaliação da produção científica: aspectos conceituais e metodológicos. Ci. Inf., Brasília, v. 34, n. 1, p.1927, jan./abr. 2005. 